in which a considerable amount of space has been devoted to the lamp-brush chromosome and its possible molecular organization.

In the last chapter, the author considers the inactivation of genes in a whole chromosome of the mouse and discusses the evidence for and against the Lyon hypothesis which offers an explanation. The position effect on gene expression and the role of heterochromatin is another topic mentioned. Reference is also made to the so-called "controlling elements", assumed by McClintock to be abnormal states of a system of genes affecting the manifestation of characters in the maize plant. The author devotes considerable space to a new concept of chromosome structure; he describes in detail the nature and implication of Callan's "master and slave" hypothesis, and draws a tentative conclusion that the "chromomere", that is to say, a linear series of copies of structural gene within the DNA molecule, is the unit of function, replication and recombination in the chromosome.

This brief outline of the contents only indicates a few of the topics which Whitehouse discusses in the book. The 250 new references, incorporated in the second edition, enrich it considerably and make it an up to date source of information for biologists, who can learn how far our understanding of the molecular basis of the hereditary mechanism has progressed since the first edition. With its good glossary and very comprehensive subject index, the scientific value of the book is greatly enhanced. Nevertheless, a warning should be given that the book must not be considered as an introduction to genetics which the reader might well assume from the title. I would recommend the book to research students specializing in a restricted field of molecular genetics who wish to gain a panoramic view of modern genetics as a whole.

\section{PLANT CELL BIOLOGY}

Plant Cells

By F. A. L. Clowes and B. E. Juniper. (Botanical Monograph, Vol. 8.) Pp. xvii +546. (Blackwell (Scientific): Oxford and Edinburgh, 1968.) $120 s$.

To decide when the time is ripe to write a comprehensive text or monograph in a newly developing field is not easy, especially when new facts are being added to the subject each month in ever-expanding journals. Plant cell biology needs such a text now and Plant Cells goes a long way to fill the need. This is a thorough plant cell biology book which considers in particular the cells of higher plants and their detailed structure at the light and electron microscope level. Further, it discusses the implications of such structure in the functioning of the cells and of the organism, and explores the implications of cellular interrelations and interdependencies for multicellular developmental problems.

The book may be divided into three parts-first, introductory technical considerations useful to cytological discussions, including a brief summary of the techniques of cell research and the problem of dimensions; second, an extended presentation of cell structure, including an excellent collection of original and informative light and electron micrographs and diagrams; and third, a stimulating discussion of cells in action, that is, the cell cycle, cell differentiation and specialization and cell heredity.

The attempt to be up to date is relatively successful: more than 30 per cent of the references cited are dated 1965 up to early 1967. The authors convey the flavour of modern cell biological research by presenting first the available evidence and then the several opposing interpretations for the many controversial issues which con-

\title{
COLLECTORS' FISHES
}

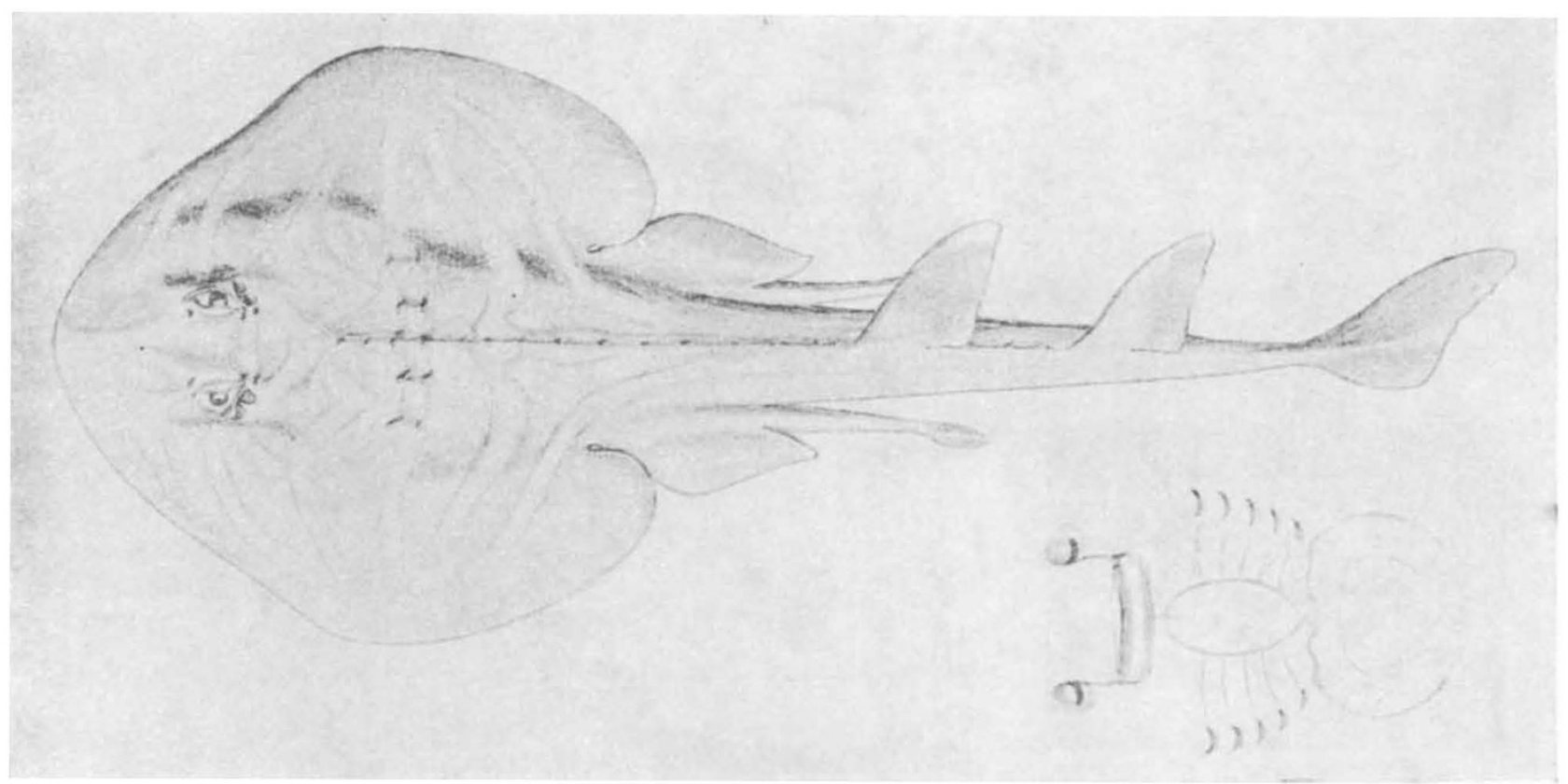

Pencil drawing of a ray by Herman Diedrich Spöring, a Swede, who was a member of Joseph Bank's natural history party aboard HMS Endeavour on the first of Captain Cook's famous voyages (1768-1771). One of the 40 drawings and sketches reproduced (all but 3 for the first time) with a text by P. J. P. Whitehead in Drawings of Fishes from Captain Cook's Voyages (Trustees of the British Museum (Natural History): London, 1968, 420s). The British Museum (Natural History) has 262 drawings made during the three voyages, 156 by S. Parkinson, 78 by G. A. Forster, 15 by W. Ellis, 7 by A. Buchan and 6 by Spöring. Some of the drawings included in this publication were used by nineteenth-century authors wholly or partly as the basis for descriptions of new species. Only a small number of the drawings were completed, the majority being sketches with washes of colour. 